\title{
Simultaneous Stochastic Volatility Transmission Across American Equity Markets
}

\author{
Enzo Weber*
}

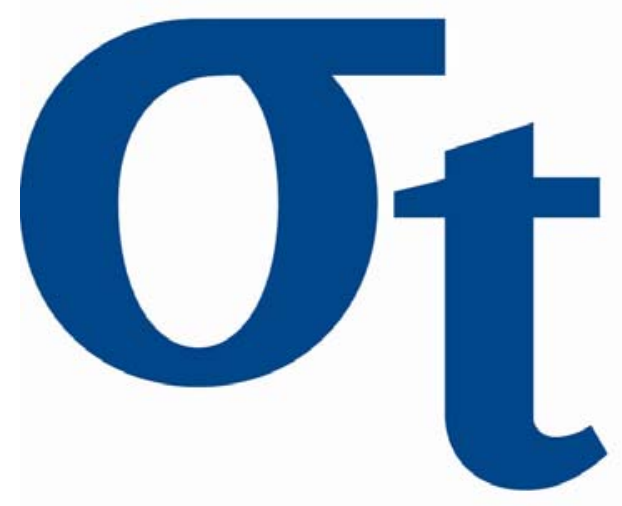

9)

$\forall$

6

* Freie Universität Berlin, Germany

This research was supported by the Deutsche Forschungsgemeinschaft through the SFB 649 "Economic Risk". 


\title{
Simultaneous Stochastic Volatility Transmission Across American Equity Markets ${ }^{1}$
}

\author{
Enzo Weber \\ Universität Mannheim and Freie Universität Berlin \\ Boltzmannstr. 20, 14195 Berlin, Germany \\ eweber@wiwiss.fu-berlin.de \\ phone: +49 (0)30 838-55792 fax: +49 (0)30 838-54142
}

First version: $03 / 2008$

This version: $05 / 2008$

\begin{abstract}
Information flows across international financial markets typically occur within hours, making volatility spillover appear contemporaneous in daily data. Such simultaneous transmission of variances is featured by the stochastic volatility model developed in this paper, in contrast to usually employed multivariate $\mathrm{ARCH}$ processes. The identification problem is solved by considering heteroscedasticity of the structural volatility innovations, and estimation takes place in an appropriately specified state space setup. In the empirical application, unidirectional volatility spillovers from the US stock market to three American countries are revealed. The impact is strongest for Canada, followed by Mexico and Brazil, which are subject to idiosyncratic crisis effects.
\end{abstract}

Keywords: Stochastic Volatility, Identification, Variance Transmission JEL classification: C32, G15

\footnotetext{
${ }^{1}$ This research was supported by the Deutsche Forschungsgemeinschaft through the CRC 649 "Economic Risk". I am grateful to Jürgen Wolters and Cordelia Thielitz for their help. Of course, all remaining errors are my own.
} 


\section{Introduction}

For the last several decades, volatility processes in financial markets have attracted a considerable amount of econometric research. Therein, the main strands can be identified as autoregressive conditional heteroscedasticity $(\mathrm{ARCH})$ and stochastic volatility $(\mathrm{SV})$. This sustained interest can be explained by the important role volatility plays in finance disciplines like risk management, portfolio allocation or asset pricing. In the same vein, the transmission of volatility between different financial segments conceived attention both of theoretical and applied research. Ross (1989), amongst others, ascribes to spillovers in variance the meaning of information flow between the concerned markets. This view is in line with connecting volatility to market activity variables like trade volume, news arrival or order flow. Furthermore, propagation of variability may be related to spreading uncertainty and contagious effects.

In the vast multivariate $\mathrm{ARCH}$ literature, causality in the second moments is necessarily represented by observed lead-lag-relations. Contemporaneous interaction is naturally incompatible with the conditional model character. However, given that efficient markets process and transmit information quite quickly, in daily data interaction indeed appears instantaneous to a large degree. The SV approach incorporates such contemporaneous commonalities in the volatility processes as correlation between the according stochastic innovations. Furthermore, SV models are closely linked to theoretical finance and continuous time approaches. For example, Tauchen and Pitts (1983) and Andersen (1996) provide microstructure speculative trading arguments for the use of SV.

This paper develops an SV model, which accounts for instantaneous variance spillover across different financial variables. Importantly, causality is not assessed on the basis of conventional approaches relying on observed time sequences. Thus, the first contribution lies in formulating a structural-form SV process in contrast to the reduced-form versions proposed in the literature (e.g. Harvey et al. 1994). Naturally, such a specification creates the problem of identifying the model simultaneity. For this reason, as a second contribution, I introduce ARCH effects for the variances of the structural SV innovations; given this time-variation, the contemporaneous structure can be identified through heteroscedasticity, see Sentana and Fiorentini (2001), Rigobon (2002) and Weber (2007a). Eventually, a state space framework is constructed that combines the unobserved SV and $\mathrm{ARCH}$ components and paves the way for Quasi Maximum Likelihood (QML) estimation.

The model is applied to major stock markets in the US, Canada, Mexico and Brazil, which exhibit large or even perfect overlap in their trading hours. Therefore, addressing 
volatility spillover conventionally as in Engle et al. (1990) or Melvin and Melvin (2003) is not feasible: These approaches focus on transmission of a single asset's volatility around the globe as different trading places open and close. In contrast, the underlying paper does not rely on such a predetermined time sequence in studying the interaction among distinct assets. Namely, the methodology is able to identify unidirectional instantaneous information flows from the S\&P 500 to the other American equity exchanges. Thereby, the US governs $8 \%$ of stock market variability in Brazil, $11 \%$ in Mexico and $60 \%$ in Canada. However, these numbers considerably rise when excluding the turbulent crisis years in the 1990s.

The paper proceeds as follows: The next section introduces the SV model and discusses estimation by QML. The empirical application is put forth in section 3, and conclusions are drawn in a summary.

\section{Methodology}

\subsection{Model and Identification}

The current paper is occupied with modelling transmission effects in the volatility domain. To keep the analysis as straight as possible, for the conditional mean a rather simple specification is chosen (see e.g. Harvey et al. 1994). In detail, assume that each of the $k$ asset returns follows the process

$$
y_{i t}=\varepsilon_{i t} e^{h_{i t} / 2} \quad i=1, \ldots, k
$$

Here, $h_{i t}$ denotes the $\log$ conditional variance of $y_{i t}$, and the $\varepsilon_{i t}$ are the mean shocks. For the vector $\varepsilon_{t}=\left(\varepsilon_{1 t}, \ldots, \varepsilon_{k t}\right)^{\prime}$ assume multivariate normality as $\varepsilon_{t} \sim N(0, \Sigma)$, where the elements on the main diagonal of $\Sigma$ are normalised to unity.

With $h_{t}=\left(h_{1 t}, \ldots, h_{k t}\right)^{\prime}$, the data generating process of the log conditional variances is described by the structural $\operatorname{VAR}(1)$ model

$$
A h_{t}=C+B h_{t-1}+\eta_{t}
$$

where $C$ is a $k$-dimensional vector of constants and $A$ and $B$ represent $k \times k$ coefficient matrices. The off-diagonal elements in $A$ mirror the contemporaneous spillovers between the volatilities. Evidently, the structural volatility process (2) is fully simultaneous and therefore unavoidably subject to the generic identification problem in SVARs. Thereby, 
(besides $C$ and $B$ ) the set of unknowns consists of $k^{2}$ parameters from $A, k(k-1) / 2$ covariances between the $\eta_{i t}$ and their $k$ variances.

Normalising the diagonal elements of $A$ to unity reduces the number of unknowns by $k$. Furthermore, due to the structural character of the model, the innovations in $\eta_{t}$ are assumed uncorrelated. Eventually, the covariance matrix of the residuals $u_{t}=A^{-1} \eta_{t}$ from the reduced form

$$
h_{t}=K+\Pi h_{t-1}+u_{t},
$$

with $K=A^{-1} C$ and $\Pi=A^{-1} B$ delivers $k(k+1) / 2$ distinct determining equations. Overall, this still leaves a lack of $k(k-1) / 2$ pieces in the pool of available information.

For solving this indeterminacy, I rely on the idea of identification through heteroscedasticity: Basically, if the $k$ variances of $\eta_{t}$ are time-varying, this property carries over to the $k$ reduced-form variances and $k(k-1) / 2$ such covariances of $u_{t}$. Obviously, each shift in variance manifests more information than it introduces additional unknowns. Instead of relying on single breaks points, ARCH processes can be employed to describe quasi continuous evolvement of volatility. In the conditional mean domain, this concept has been pointed out for example by Sentana and Fiorentini (2001) and Weber (2007b) for factor models as well as by Rigobon (2002) and Weber (2007a) for SVARs. As an important modification, here I adapt the principle to identification of simultaneity in variance.

For explicit parameterisation, assume $\eta_{t} \sim N\left(0, \Omega_{t}\right)$, where $\Omega_{t}$ contains $\omega_{1 t}, \ldots, \omega_{k t}$ on the main diagonal and zeros off-diagonal. Let the time-varying conditional variances $\omega_{i t}$ follow the $\operatorname{GARCH}(1,1)$ processes

$$
\omega_{i t}=\left(1-d_{i}-g_{i}\right) \omega_{i}+d_{i} \eta_{i t-1}^{2}+g_{i} \omega_{i t-1} \quad i=1, \ldots, k
$$

where $\omega_{i}$ denotes the $i$ th unconditional variance and $d_{i}$ and $g_{i}$ are the $\mathrm{ARCH}$ and GARCH parameters. Due to the conditional uncorrelatedness of the innovations, besides the variances no conditional covariances have to be considered. Since (4) describes the heteroscedasticity of the shocks to volatility, it implies time variation in the fourth moments, that is the kurtosis of the stock returns. Time-varying kurtosis has been well established in a literature oriented at extending the ARCH approach; see Hansen (1994) for an early contribution. Furthermore, an interesting parallel can be found in Corsi et al. (2008), who specified GARCH variances for the residuals of a realised volatility model. In general, (4) merely serves as an empirically pragmatic approximation. Notwithstanding this ad hoc character, the applications in section 3 will confirm that ARCH processes provide a reasonable description of the heteroscedasticity and allow achieving appropriate identification. 


\subsection{Estimation}

If $h_{t}$ was observable, estimation by Maximum Likelihood would be straightforward. However, since stochastic volatility represents a latent process, Kalman filtering is employed to determine optimal linear estimates for the variance factors. In order to set up an according state space model, (1) is squared and linearised by taking logarithms, arriving at

$$
\log y_{i t}^{2}=h_{i t}+\log \varepsilon_{i t}^{2} \quad i=1, \ldots, k .
$$

The expectation of the logged squared residuals is known to be $E\left(\log \varepsilon_{i t}^{2}\right)=\psi(0.5)-\log 0.5$, where $\psi$ denotes the Digamma function (see Abramovitz and Stegun 1970). Therefore, defining $\varepsilon_{t}^{*}=\left\{\log \varepsilon_{i t}^{2}-E\left(\log \varepsilon_{i t}^{2}\right)\right\}$ and $y_{t}^{*}=\left\{\log y_{i t}^{2}\right\}$, the observation equations can be written as

$$
y_{t}^{*}=(\psi(0.5)-\log 0.5)+h_{t}+\varepsilon_{t}^{*} .
$$

Furthermore, the transition equations are given by the reduced form (3) of the SVAR volatility process $(2)$.

Normally, with the observation and transition equations at hand, standard Kalman filtering can be directly applied. This delivers expected (filtered) mean and variance of the factors, conditional on the observable information set containing the $y_{t}^{*}$ and all its lags. In the present case however, note that the GARCH variances in (4) depend on the squared innovations $\eta_{i t}^{2}$. As in Harvey et al. (1992), these are evaluated at their conditional expectation

$$
E_{t}\left(\eta_{t} \odot \eta_{t}\right)=E_{t}\left(\eta_{t}\right) \odot E_{t}\left(\eta_{t}\right)+\operatorname{diag}\left(\operatorname{Cov}_{t}\left(\eta_{t}\right)\right)
$$

The time index $t$ at the expectation and covariance operators stands for the abovementioned conditioning, $\odot$ denotes element-by-element multiplication, and the diag operator stacks the main diagonal of a matrix into a column vector. Since $\eta_{t}=A u_{t}$ by definition from (3), in terms of the transition errors $u_{t}$, (7) becomes

$$
E_{t}\left(\eta_{t} \odot \eta_{t}\right)=\left(A E_{t}\left(u_{t}\right)\right) \odot\left(A E_{t}\left(u_{t}\right)\right)+\operatorname{diag}\left(A \operatorname{Cov}_{t}\left(u_{t}\right) A^{\prime}\right)
$$

Therefore, the evaluation of the GARCH processes evidently requires conditional mean and variance of the reduced-form disturbances (transition errors) $u_{t}$, and not just of the factors $h_{t}$ themselves, as usual. Since the Kalman procedure yields these moments only for the state variables, $h_{t}$ has to be complemented by $u_{t}$ in the state vector. Then, given appropriate starting values, the prediction step in the recursive filtering procedure consists 
of the following equations:

$$
\begin{aligned}
& E_{t-1}\left(\begin{array}{l}
h_{t} \\
u_{t}
\end{array}\right)=\left(\begin{array}{c}
K \\
0
\end{array}\right)+\left(\begin{array}{ll}
\Pi & 0 \\
0 & 0
\end{array}\right) E_{t-1}\left(\begin{array}{l}
h_{t-1} \\
u_{t-1}
\end{array}\right) \\
& \operatorname{Cov}_{t-1}\left(\begin{array}{l}
h_{t} \\
u_{t}
\end{array}\right)=\left(\begin{array}{cc}
\Pi & 0 \\
0 & 0
\end{array}\right) \operatorname{Cov}_{t-1}\left(\begin{array}{l}
h_{t-1} \\
u_{t-1}
\end{array}\right)\left(\begin{array}{cc}
\Pi^{\prime} & 0 \\
0 & 0
\end{array}\right)+\iota \iota^{\prime} \otimes A^{-1} \Omega_{t}\left(A^{-1}\right)^{\prime} \\
& E_{t-1}\left(y_{t}^{*}\right)=(\psi(0.5)-\log 0.5)+\left(\begin{array}{ll}
I & 0
\end{array}\right) E_{t-1}\left(\begin{array}{c}
h_{t} \\
u_{t}
\end{array}\right) \\
& \operatorname{Cov}_{t-1}\left(y_{t}^{*}\right)=\left(\begin{array}{ll}
I & 0
\end{array}\right) \operatorname{Cov}_{t-1}\left(\begin{array}{l}
h_{t} \\
u_{t}
\end{array}\right)\left(\begin{array}{c}
I \\
0
\end{array}\right)+\operatorname{Cov}\left(\varepsilon_{t}^{*}\right)
\end{aligned}
$$

$\iota$ is a vector of $k$ ones and $\otimes$ denotes the Kronecker product. $\operatorname{Cov}\left(\varepsilon_{t}^{*}\right)$ contains $\pi^{2} / 2$ on the main diagonal, that is the variance of logged squared standard normal random variables. The off-diagonal parameters have to be estimated and uniquely relate to the correlations of the $\varepsilon_{i t}$ in $\Sigma$, as shown in Harvey et al. (1994). Updating of the first two factor moments takes place in the correction step, which completes the Kalman recursion:

$$
\begin{aligned}
& E_{t}\left(\begin{array}{c}
h_{t} \\
u_{t}
\end{array}\right)=E_{t-1}\left(\begin{array}{c}
h_{t} \\
u_{t}
\end{array}\right)+\operatorname{Cov}_{t-1}\left(\begin{array}{l}
h_{t} \\
u_{t}
\end{array}\right)\left(\begin{array}{l}
I \\
0
\end{array}\right)\left[\operatorname{Cov}_{t-1}\left(y_{t}^{*}\right)\right]^{-1}\left(y_{t}^{*}-E_{t-1}\left(y_{t}^{*}\right)\right) \\
& \operatorname{Cov}_{t}\left(\begin{array}{l}
h_{t} \\
u_{t}
\end{array}\right)=\operatorname{Cov}_{t-1}\left(\begin{array}{l}
h_{t} \\
u_{t}
\end{array}\right)-\operatorname{Cov}_{t-1}\left(\begin{array}{l}
h_{t} \\
u_{t}
\end{array}\right)\left(\begin{array}{l}
I \\
0
\end{array}\right)\left[\operatorname{Cov}_{t-1}\left(y_{t}^{*}\right)\right]^{-1}\left(\begin{array}{ll}
I & 0
\end{array}\right) \operatorname{Cov}_{t-1}\left(\begin{array}{c}
h_{t} \\
u_{t}
\end{array}\right)
\end{aligned}
$$

Since $\log \varepsilon_{i t}^{2}$ is clearly non-Gaussian, Quasi Maximum Likelihood is employed as an approximation (Ruiz 1994). In this context, note that the signal to noise ratio in log-linearised SV models is known to be quite unfavourable. Notwithstanding, in the following empirical application even the relatively simple QML allows to demonstrate the main point of this paper, namely obtaining evidence for SV spillover. I apply the BHHH algorithm (Berndt et al. 1974) to numerically maximise the log-likelihood function

$$
L(\theta)=-\frac{1}{2} \sum_{t=1}^{T}\left(n \log 2 \pi+\log \left|\operatorname{Cov}_{t-1}\left(y_{t}^{*}\right)\right|+\left(y_{t}^{*}-E_{t-1}\left(y_{t}^{*}\right)\right)^{\prime}\left[\operatorname{Cov}_{t-1}\left(y_{t}^{*}\right)\right]^{-1}\left(y_{t}^{*}-E_{t-1}\left(y_{t}^{*}\right)\right)\right) .
$$

The vector $\theta$ stacks all free parameters, in details those from $A, B, \Sigma, \omega_{i}, d_{i}$ and $g_{i}$, $i=1, \ldots, k$. 


\section{Application to American Equity Markets}

\subsection{Data}

In this section, I present the application to a set of American stock indices. As will be seen, this provides both interesting economic implications as well as illustration of the usefulness of the developed methodology. In detail, daily closing prices of the US S\&P 500, the Canadian S\&P/TSX Composite, the Mexican IPC and the Brazilian Ibovespa for the sample 01/02/1989 until 03/31/2008 have been collected from Reuters. Weekends and holidays are uniformly excluded. Since the locations of the involved stock exchanges differ in longitude but little in latitude, the trading times have a large to perfect overlap. ${ }^{2}$ Hence, on a daily basis, data are observed truly contemporaneously, doing justice to the discussion in the introduction and the simultaneous structure of the model from the preceding section. Figure 1 shows continuously compounded daily returns.

The starting point has been chosen as to gain a comfortable number of observations but to exclude the Black Monday in 1987 and its repercussions. Nonetheless, as can be seen from the returns, a number of crises remain in the sample, especially connected to Latin America. Therefore, I will check for the change of estimation outcomes in shortened samples, thereby shedding light on the role of economic turbulences for financial transmission processes. At last, I note that alternative stock indices such as the Dow Jones Industrial Average or the IBrX-50 were tried, without relevant changes in what follows in the next sections.

\subsection{Specification and Estimation}

Here, I exemplify the simultaneous SV model by bivariate systems including stock returns of the US and each of Canada, Mexico and Brazil. These experiments will first reveal intraday informational relations of several important stock exchanges with the world's leading equity market. Second, they allow an indirect practical assessment of the identification method in that a clear US dominance can be expected to emerge from the simultaneous interaction.

\footnotetext{
${ }^{2}$ Trading hours in New York and Toronto are 9.30 am until 4 pm local time (UTC-5 / UTC-4 during daylight saving time). Chicago and Mexico City are located in a different time zone (UTC-6 / UTC-5), but trade nonetheless perfectly aligned to Wall Street. Solely São Paulo, opening at 10 am and closing at $5 \mathrm{pm}$ local time (UTC-3 / UTC-2), differs by 90 respectively 60 minutes. However, since results concerning Brazil will be in line with the remaining ones, I suspect no decisive bias.
} 

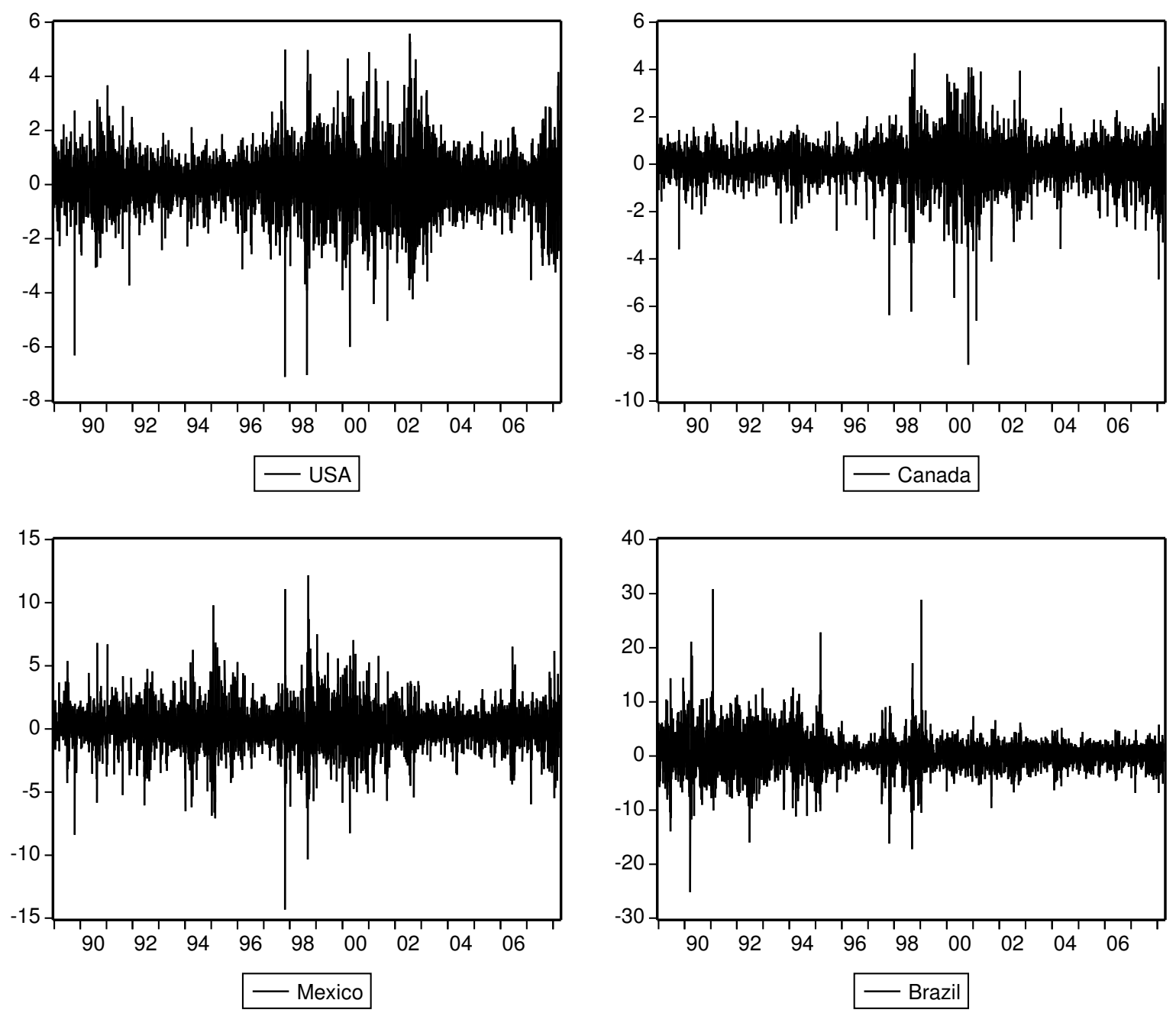

Figure 1: Major stock index returns

In a first step, the return series are adjusted for their unconditional means. Then, the likelihood (15) is optimised to retain estimates for the model (1), (2), (4). Thereby, the autoregressive matrices $\Pi$ emerged as virtually diagonal, so that this restriction has been formally imposed; compare as well Harvey et al. (1994). Furthermore, no significant GARCH effects $g_{i}$ could be detected, leading to pure $\mathrm{ARCH}(1)$ specifications for the volatility innovations. A similar constellation can be found in Corsi et al. (2008), who estimate $\operatorname{GARCH}(1,1)$ processes for the residuals of a realised volatility model and find very low values for the GARCH parameters. 


\subsection{Results and Discussion}

Table 1 presents the SV and ARCH results for the three bivariate models. Most importantly, I find strong contemporaneous impacts from US to foreign volatility, even though the coefficient in the Brazilian equation is only borderline significant at the $10 \%$ level. In contrast, the reverse effects are totally insignificant and in two cases even negative ${ }^{3}$. Thus, the developed identification methodology delivers results consistent with a priori expectations. Note that since US volatility is largely exogenous, the outcome for its equation hardly depends on the particular pairing. For the structural SV innovations, highly significant $\mathrm{ARCH}(1)$-effects are detected, which are in some cases close to non-stationarity. As usual, SV shows strong persistence, and the correlation of mean shocks is highest for the US and Canada (32\%), followed by Mexico (27\%) and Brazil (22\%). ${ }^{4}$ Since the unconditional correlations of returns amount to $66 \%, 44 \%$ and $27 \%$ and these arise from the mixed distribution decomposition (1), one can infer that for Canada and Mexico, a considerable part of the comovement arises from variance spillover. Before addressing this issue, let us restrict the insignificant effects on US volatility to zero in order to prevent them from distorting economic interpretation; results are in Table (2).

\begin{tabular}{|c|c|c|c|c|c|c|}
\hline & $K$ & $\Pi$ & $A$ & $\operatorname{Cor}\left(\varepsilon_{1 t}^{*}, \varepsilon_{2 t}^{*}\right)$ & $\omega$ & $d$ \\
\hline Canada & $\begin{array}{r}-0.005 \\
(0.003)\end{array}$ & $\begin{array}{l}0.993 \\
(0.003)\end{array}$ & $\begin{array}{r}-0.969 \\
(0.299)\end{array}$ & $\begin{array}{l}0.218 \\
(0.014)\end{array}$ & $\begin{array}{l}0.001 \\
(0.003)\end{array}$ & $\begin{array}{l}0.999 \\
(0.0001)\end{array}$ \\
\hline USA & $\begin{array}{r}-0.003 \\
(0.002)\end{array}$ & $\begin{array}{l}0.996 \\
(0.002)\end{array}$ & $\begin{array}{l}0.101 \\
(0.311)\end{array}$ & {$[=32 \%]$} & $\begin{array}{l}0.007 \\
(0.004)\end{array}$ & $\begin{array}{l}0.995 \\
(0.003)\end{array}$ \\
\hline Mexico & $\begin{array}{l}0.013 \\
(0.011)\end{array}$ & $\begin{array}{l}0.963 \\
(0.039)\end{array}$ & $\begin{array}{r}-0.802 \\
(0.314)\end{array}$ & $\begin{array}{l}0.148 \\
(0.014)\end{array}$ & $\begin{array}{l}0.034 \\
(0.048)\end{array}$ & $\begin{array}{l}0.834 \\
(0.070)\end{array}$ \\
\hline USA & $\begin{array}{r}-0.002 \\
(0.002) \\
\end{array}$ & $\begin{array}{l}0.996 \\
(0.002) \\
\end{array}$ & $\begin{array}{r}-0.036 \\
(0.055) \\
\end{array}$ & {$[=27 \%]$} & $\begin{array}{l}0.006 \\
(0.002) \\
\end{array}$ & $\begin{array}{l}0.977 \\
(0.019) \\
\end{array}$ \\
\hline Brazil & $\begin{array}{l}0.007 \\
(0.004)\end{array}$ & $\begin{array}{l}0.996 \\
(0.002)\end{array}$ & $\begin{array}{r}-0.821 \\
(0.500)\end{array}$ & $\begin{array}{l}0.098 \\
(0.013)\end{array}$ & $\begin{array}{l}0.009 \\
(0.004)\end{array}$ & $\begin{array}{l}0.903 \\
(0.067)\end{array}$ \\
\hline USA & $\begin{array}{r}-0.002 \\
(0.002)\end{array}$ & $\begin{array}{l}0.996 \\
(0.002)\end{array}$ & $\begin{array}{l}0.437 \\
(0.349)\end{array}$ & {$[=22 \%]$} & $\begin{array}{l}0.010 \\
(0.006)\end{array}$ & $\begin{array}{c}0.999 \\
(0.0006)\end{array}$ \\
\hline
\end{tabular}

Table 1: Estimates for SV and ARCH equations

Here, one finds that unit shocks to US volatility spill over to Canada and Mexico by a good $80 \%$, but by barely half of it to Brazil. Based on these numbers, I calculate correlations and variance decompositions of shocks to volatility. Note that while these

\footnotetext{
${ }^{3}$ Remember that $A$ stands left hand side in (2), so that in fact coefficient signs have to be reversed.

${ }^{4}$ The estimated correlations are those of the transformed shocks $\varepsilon_{i t}^{*}=\log \varepsilon_{i t}^{2}-E\left(\varepsilon_{i t}^{2}\right)$. Implied correlations of the original $\varepsilon_{i t}$ are given in brackets.
} 
summary measures are quite informative, their exact magnitude is subject to uncertainty due to the relatively imprecise estimates of the $\mathrm{ARCH}$ constants $\omega$. To begin with, the reduced-form residuals $u_{t}$ from (3) exhibit unconditional parametric correlations of $77 \%$, $39 \%$ and $28 \%$ (in the same order as before). This confirms the above considerations on the contribution of volatility to overall return correlation. Furthermore, one can decompose the variability of $u_{1 t}$, the disturbance to foreign $\mathrm{SV}$, into portions governed by own and US shocks $\eta_{1 t}$ and $\eta_{2 t}$, respectively. In doing so, I find a US contribution of $60 \%$ to Canadian, $11 \%$ to Mexican and $8 \%$ to Brazilian SV.

\begin{tabular}{|c|c|c|c|c|c|c|}
\hline & $K$ & $\Pi$ & $A$ & $\operatorname{Cor}\left(\varepsilon_{1 t}^{*}, \varepsilon_{2 t}^{*}\right)$ & $\omega$ & $d$ \\
\hline Canada & $\begin{array}{r}-0.006 \\
(0.003)\end{array}$ & $\begin{array}{l}0.995 \\
(0.002)\end{array}$ & $\begin{array}{r}-0.882 \\
(0.195)\end{array}$ & $\begin{array}{l}0.218 \\
(0.014)\end{array}$ & $\begin{array}{l}0.003 \\
(0.001)\end{array}$ & $\begin{array}{l}0.996 \\
(0.003)\end{array}$ \\
\hline USA & $\begin{array}{r}-0.003 \\
(0.002) \\
\end{array}$ & $\begin{array}{l}0.995 \\
(0.002)\end{array}$ & 0 & {$[=32 \%]$} & $\begin{array}{l}0.005 \\
(0.003)\end{array}$ & $\begin{array}{l}0.999 \\
(0.001)\end{array}$ \\
\hline Mexico & $\begin{array}{l}0.010 \\
(0.009)\end{array}$ & $\begin{array}{l}0.968 \\
(0.029)\end{array}$ & $\begin{array}{r}-0.822 \\
(0.293)\end{array}$ & $\begin{array}{l}0.147 \\
(0.014)\end{array}$ & $\begin{array}{l}0.028 \\
(0.034)\end{array}$ & $\begin{array}{l}0.892 \\
(0.105)\end{array}$ \\
\hline USA & $\begin{array}{r}-0.003 \\
(0.002) \\
\end{array}$ & $\begin{array}{l}0.995 \\
(0.003) \\
\end{array}$ & 0 & {$[=27 \%]$} & $\begin{array}{l}0.005 \\
(0.003) \\
\end{array}$ & $\begin{array}{c}0.999 \\
(0.0007) \\
\end{array}$ \\
\hline Brazil & $\begin{array}{l}0.007 \\
(0.004)\end{array}$ & $\begin{array}{l}0.996 \\
(0.002)\end{array}$ & $\begin{array}{r}-0.371 \\
(0.224)\end{array}$ & $\begin{array}{l}0.098 \\
(0.013)\end{array}$ & $\begin{array}{l}0.008 \\
(0.003)\end{array}$ & $\begin{array}{l}0.905 \\
(0.053)\end{array}$ \\
\hline USA & $\begin{array}{r}-0.003 \\
(0.002) \\
\end{array}$ & $\begin{array}{l}0.996 \\
(0.002) \\
\end{array}$ & 0 & {$[=22 \%]$} & $\begin{array}{l}0.005 \\
(0.004) \\
\end{array}$ & $\begin{array}{c}0.999 \\
(0.0006) \\
\end{array}$ \\
\hline \multicolumn{7}{|c|}{$\begin{array}{l}\text { Notes: } K \text { : constants; } \Pi \text { : diagonal of AR-matrix; } A \text { : off-diagonal elements } \\
\text { of contemporaneous matrix; } \operatorname{Cor}\left(\varepsilon_{1 t}^{*}, \varepsilon_{2 t}^{*}\right): \operatorname{Cor}\left(\varepsilon_{1 t}, \varepsilon_{2 t}\right) \text { in brackets; } \\
\omega: \text { ARCH constants; } d \text { : ARCH parameters }\end{array}$} \\
\hline
\end{tabular}

Table 2: Restricted estimates for SV and ARCH equations

Figure 2 clarifies how the differences in results can be explained. Especially in the Mexican and Brazilian SVs, a number of crises stand out, namely the peso crisis in 1994, the Asian financial crisis in 1997, the Russian bond default in 1998 and the Brazilian currency crisis in 1999. In contrast, for the US ${ }^{5}$ and Canada, the time around the 2001 recession and the 9/11 attacks plays a more distinctive role. In consequence, as the results have shown, the akin North American markets are tightly connected, whereas Mexico and even more so Brazil are subject to far stronger idiosyncratic or Latin America specific shocks. Nevertheless, a "baseline" flow of US information has as well been detected for these two countries, even if it does not account for the bulk of news arriving.

In view of the several turbulent crisis periods, strong idiosyncratic volatility components especially for Brazil are not surprising. In order to uncover the influence of such events on the spillover results, I shift the sample starting point to the second half of 1999 . This

\footnotetext{
${ }^{5}$ US SVs from the three models are practically identical.
} 

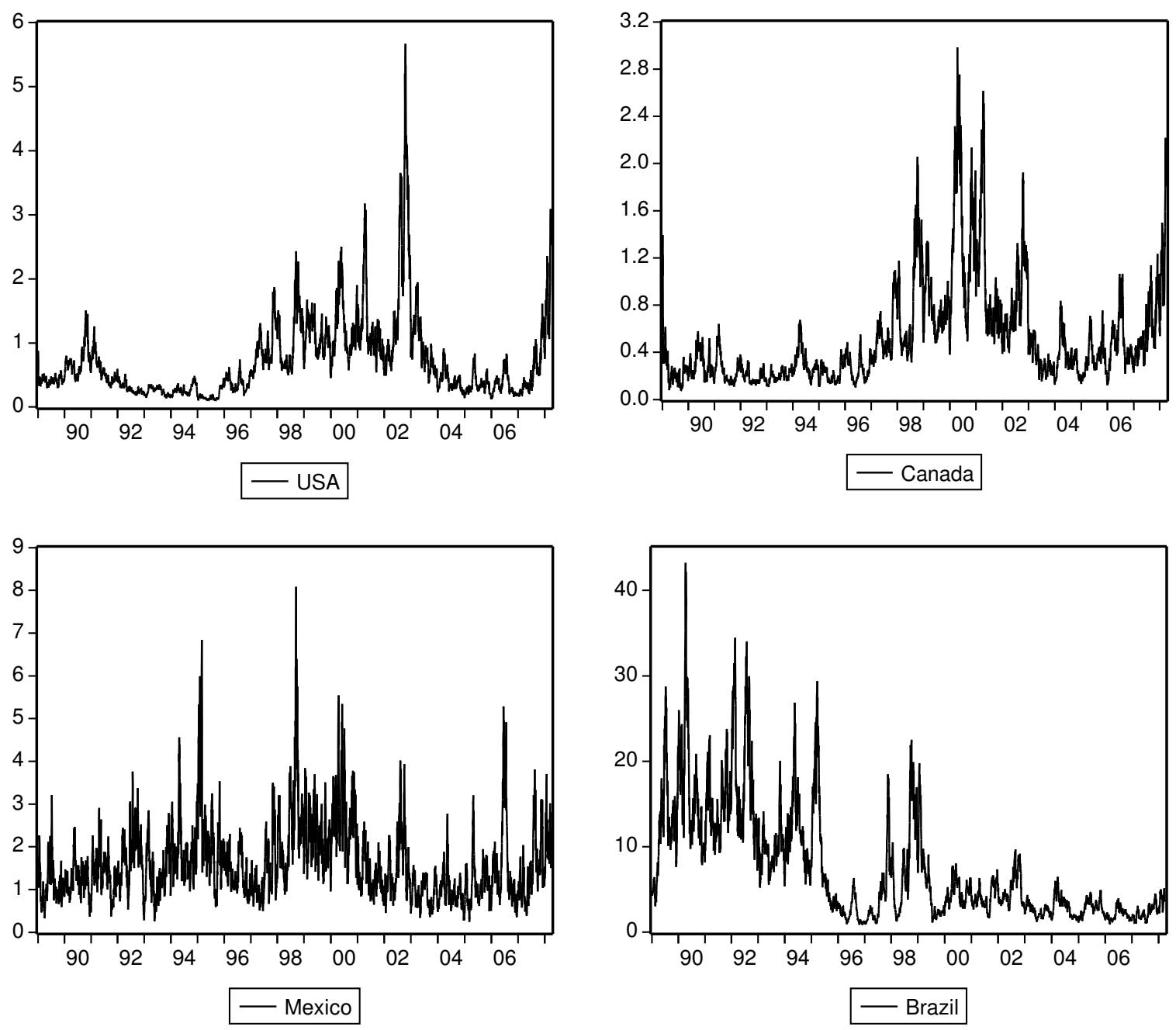

Figure 2: Stochastic volatilities

choice excludes the Asian, Russian and Brazilian crises, as has been argued above; see as well Figures 1 and 2. Shortening the sample does not change insignificance of foreign influences on the US, so that the according zero constraints are maintained.

Instead of again reporting the whole set of coefficients, which are now clearly significant for all countries including Brazil, I concentrate on the summary measures correlation and US variance contribution. These magnitudes rise to $97 \%$ and $94 \%$ for Canada, $94 \%$ and $88 \%$ for Mexico as well as $62 \%$ and $38 \%$ for Brazil, respectively. While numbers for the latter might be of reasonable size, Canada and Mexico reveal an extreme dependence. Even though such an outcome is not necessarily unrealistic for both of these US neighbour countries, one should note that the shortened sample is largely dominated by the period of high volatility in the first years of the new decade. Here, the underlying events are likely to trigger close comovement, the more so as $9 / 11$ and the 2001 recession are likely to make US 
information lead short- and medium-term orientation of world financial markets. Starting the sample in 2003, thus leaving behind the turbulent years, yields values in between the two extreme results of distinct idiosyncratic driving forces and strong US dominance.

Besides implying interesting consequences in terms of economics, from the statistical point of view, the different results point at potential merits of a time-varying approach, such as given in Lopes and Carvalho (2007) for the reduced form. Even though the present paper already allows for time variation in the variances of the first and second moment innovations, flexibility could be further increased for example by considering non-constant spillover coefficients.

In order to test whether the model appropriately picked up the heteroscedasticity in the measurement and transition errors, autocorrelations of squared ${ }^{6}$ disturbances, standardised by their conditional variances, were checked to not exceed their two standard error bands. Thereby, the variances of the mean shocks $y_{i t}$ are simply given by the SV $e^{h_{i t}}$, while for the residuals $u_{i t}$ of the SV processes themselves, the ARCH variances are obtained from the diagonal of $A^{-1} \Omega_{t}\left(A^{-1}\right)^{\prime}$, see (10). For the latter, the underlying choice of $\mathrm{ARCH}$ specifications is supported, since standardisation renders autocorrelations generally insignificant; the same can be inferred from Q-statistics. The only exception is Brazil, where a few significant serial correlations were found, which were however not persistent. The picture is somewhat different for the squared innovations to the returns, since statistically significant remaining autocorrelations appear on the first few orders. However, these are rather small (mostly far below 10\%), the more so as when one considers the enormous reduction in autocorrelation of squared returns achieved by standardisation. Furthermore, this moderate remaining persistence is not triggered by the special underlying model specification, because conventional univariate SV estimations happened to suffer from the very same problem.

\section{Concluding Summary}

This paper proposed a stochastic volatility model for estimating contemporaneous effects of causality in variance. In a unified approach, volatility factors, instantaneous spillovers and structural SV innovations are estimated. Furthermore, the variances of the latter are specified as GARCH processes, so that the model simultaneity can be identified through heteroscedasticity. A state space setup is constructed, which allows handling these com-

\footnotetext{
${ }^{6}$ Conditional expectations of squared factor states have been calculated following the principle of (7).
} 
ponents, that is unobserved volatility, its innovations and the according conditional variances, by means of Kalman filtering.

Notable results are obtained in the application of the methodology to major equity indices of the US, Canada, Mexico and Brazil. The estimations confirm the presence of unidirectional information flows alias volatility spillovers that originate in the US equity market. Thereby, the bounds of Canada to the US prove especially tight. In contrast, Mexico and especially Brazil were subject to a number of more or less idiosyncratic crisis events in the 1990s, leaving only a subordinate role to the US influence in the determination of overall stock market variability. Accordingly, sufficient sample shortening noticeably increases the dependence on impulses originating in the US.

The present approach bears significant potential for future research: The new element of simultaneous SV spillover can be combined with more complex models already existing in reduced form, for instance allowing for time-varying correlations, jumps or common factors. Especially the last point would contribute to the model's appeal, since it would overcome the need to explain comovement exclusively by spillovers between the variances of the included variables (see Weber 2007b). In the same vein, one could obtain economically interpretable SV factor structures that do not suffer from rotational indeterminacy, as it has been encountered for instance by Harvey et al. (1994). Efficiency gains could be realised by replacing the QML method by more recently developed simulation-based estimation techniques. At last, the proposed methodology could be applied to further economic issues such as given in the contagion literature and be compared to causalityin-variance results from multivariate ARCH-type models.

\section{References}

[1] Abramovitz, M., N. Stegun (1970): Handbook of mathematical functions. Dover Publications, New York, NY.

[2] Andersen, T.G. (1996): Return volatility and trading volume: An information flow interpretation of stochastic volatility. Journal of Finance 51, 169-204.

[3] Berndt, E., B. Hall, R. Hall, J. Hausman (1974): Estimation and Inference in Nonlinear Structural Models. Annals of Social Measurement, 3, 653-665.

[4] Corsi, F., S. Mittnik, C. Pigorsch, U. Pigorsch (2008): The Volatility of Realized Volatility. Forthcoming in Econometric Reviews. 
[5] Engle, R.F., T. Ito, W. Lin (1990): Meteor Showers or Heat Waves? Heteroscedastic Intradaily Volatility in the Foreign Exchange Market. Econometrica, 59, 525-542.

[6] Hansen, B.E. (1994): Autoregressive Conditional Density Estimation. International Economic Review, 35, 705-730.

[7] Harvey, A., E. Ruiz, E. Sentana (1992): Unobservable component time series models with arch disturbances. Journal of Econometrics 52, 129-158.

[8] Harvey, A., E. Ruiz, N. Shephard (1994): Multivariate Stochastic Variance Models. The Review of Economic Studies, 61, 247-264.

[9] Lopes, H.F., C.M. Carvalho (2007): Factor stochastic volatility with time varying loadings and Markov switching regimes. Journal of Statistical Planning and Inference, 137, 3082-3091.

[10] Melvin, M., B. Melvin (2003): The Global Transmission of Volatility in the Foreign Exchange Market. Review of Economics and Statistics, 85, 670-679.

[11] Rigobon, R. (2002): The Curse of Non-Investment Grade Countries. Journal of Development Economics, 69, 423-449.

[12] Ross, S.A. (1989): Information and volatility: the no-arbitrage martingale approach to timing and resolution irrelevancy. Journal of Finance, 44, 1-17.

[13] Ruiz, E. (1994): Quasi-maximum likelihood estimation of stochastic volatility models. Journal of Econometrics, 63, 289-306.

[14] Sentana, E., G. Fiorentini (2001): Identification, estimation and testing of conditionally heteroskedastic factor models. Journal of Econometrics, 102, 143-164.

[15] Tauchen, G.E., M. Pitts (1983): The price variability-volume relationship on speculative markets. Econometrica 51, 485-505.

[16] Weber, E. (2007a): Volatility and Causality in Asia Pacific Financial Markets. CRC 649 Discussion Paper 2007-004, Humboldt-Universität zu Berlin.

[17] Weber, E. (2007b): Correlation vs. Causality in Stock Market Comovement. CRC 649 Discussion Paper 2007-064, Humboldt-Universität zu Berlin. 


\section{SFB 649 Discussion Paper Series 2008}

For a complete list of Discussion Papers published by the SFB 649, please visit http://sfb649. wiwi. hu-berlin.de.

001 "Testing Monotonicity of Pricing Kernels" by Yuri Golubev, Wolfgang Härdle and Roman Timonfeev, J anuary 2008.

002 "Adaptive pointwise estimation in time-inhomogeneous time-series models" by Pavel Cizek, Wolfgang Härdle and Vladimir Spokoiny, January 2008.

003 "The Bayesian Additive Classification Tree Applied to Credit Risk Modelling" by Junni L. Zhang and Wolfgang Härdle, January 2008.

004 "Independent Component Analysis Via Copula Techniques" by Ray-Bing Chen, Meihui Guo, Wolfgang Härdle and Shih-Feng Huang, January 2008.

005 "The Default Risk of Firms Examined with Smooth Support Vector Machines" by Wolfgang Härdle, Yuh-Jye Lee, Dorothea Schäfer and Yi-Ren Yeh, January 2008.

006 "Value-at-Risk and Expected Shortfall when there is long range dependence" by Wolfgang Härdle and J ulius Mungo, Januray 2008.

007 "A Consistent Nonparametric Test for Causality in Quantile" by Kiho Jeong and Wolfgang Härdle, January 2008.

008 "Do Legal Standards Affect Ethical Concerns of Consumers?" by Dirk Engelmann and Dorothea Kübler, January 2008.

009 "Recursive Portfolio Selection with Decision Trees" by Anton Andriyashin, Wolfgang Härdle and Roman Timofeev, January 2008.

010 "Do Public Banks have a Competitive Advantage?" by Astrid Matthey, January 2008.

011 "Don't aim too high: the potential costs of high aspirations" by Astrid Matthey and Nadja Dwenger, January 2008.

012 "Visualizing exploratory factor analysis models" by Sigbert Klinke and Cornelia Wagner, January 2008.

013 "House Prices and Replacement Cost: A Micro-Level Analysis" by Rainer Schulz and Axel Werwatz, January 2008.

014 "Support Vector Regression Based GARCH Model with Application to Forecasting Volatility of Financial Returns" by Shiyi Chen, Kiho Jeong and Wolfgang Härdle, January 2008.

015 "Structural Constant Conditional Correlation" by Enzo Weber, January 2008.

016 "Estimating Investment Equations in Imperfect Capital Markets" by Silke Hüttel, Oliver Mußhoff, Martin Odening and Nataliya Zinych, January 2008.

017 "Adaptive Forecasting of the EURIBOR Swap Term Structure" by Oliver Blaskowitz and Helmut Herwatz, January 2008.

018 "Solving, Estimating and Selecting Nonlinear Dynamic Models without the Curse of Dimensionality" by Viktor Winschel and Markus Krätzig, February 2008.

019 "The Accuracy of Long-term Real Estate Valuations" by Rainer Schulz, Markus Staiber, Martin Wersing and Axel Werwatz, February 2008.

020 "The Impact of International Outsourcing on Labour Market Dynamics in Germany" by Ronald Bachmann and Sebastian Braun, February 2008.

021 "Preferences for Collective versus Individualised Wage Setting" by Tito Boeri and Michael C. Burda, February 2008.

\section{SFB 649, Spandauer Straße 1, D-10178 Berlin http:/ / sfb649.wiwi.hu-berlin.de}

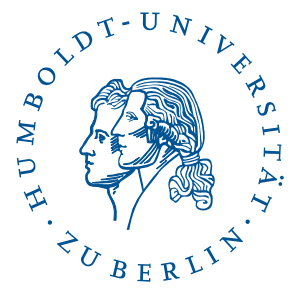


022 "Lumpy Labor Adjustment as a Propagation Mechanism of Business Cycles" by Fang Yao, February 2008.

023 "Family Management, Family Ownership and Downsizing: Evidence from S\&P 500 Firms" by Jörn Hendrich Block, February 2008.

024 "Skill Specific Unemployment with Imperfect Substitution of Skills" by Runli Xie, March 2008.

025 "Price Adjustment to News with Uncertain Precision" by Nikolaus Hautsch, Dieter Hess and Christoph Müller, March 2008.

026 "Information and Beliefs in a Repeated Normal-form Game" by Dietmar Fehr, Dorothea Kübler and David Danz, March 2008.

027 "The Stochastic Fluctuation of the Quantile Regression Curve" by Wolfgang Härdle and Song Song, March 2008.

028 "Are stewardship and valuation usefulness compatible or alternative objectives of financial accounting?" by J oachim Gassen, March 2008.

029 "Genetic Codes of Mergers, Post Merger Technology Evolution and Why Mergers Fail" by Alexander Cuntz, April 2008.

030 "Using R, LaTeX and Wiki for an Arabic e-learning platform" by Taleb Ahmad, Wolfgang Härdle, Sigbert Klinke and Shafeeqah Al Awadhi, April 2008.

031 "Beyond the business cycle - factors driving aggregate mortality rates" by Katja Hanewald, April 2008.

032 "Against All Odds? National Sentiment and Wagering on European Football" by Sebastian Braun and Michael Kvasnicka, April 2008.

033 "Are CEOs in Family Firms Paid Like Bureaucrats? Evidence from Bayesian and Frequentist Analyses" by Jörn Hendrich Block, April 2008.

034 "JBendge: An Object-Oriented System for Solving, Estimating and Selecting Nonlinear Dynamic Models" by Viktor Winschel and Markus Krätzig, April 2008.

035 "Stock Picking via Nonsymmetrically Pruned Binary Decision Trees" by Anton Andriyashin, May 2008.

036 "Expected Inflation, Expected Stock Returns, and Money Illusion: What can we learn from Survey Expectations?" by Maik Schmeling and Andreas Schrimpf, May 2008.

037 "The Impact of Individual Investment Behavior for Retirement Welfare: Evidence from the United States and Germany" by Thomas Post, Helmut Gründl, J oan T. Schmit and Anja Zimmer, May 2008.

038 "Dynamic Semiparametric Factor Models in Risk Neutral Density Estimation" by Enzo Giacomini, Wolfgang Härdle and Volker Krätschmer, May 2008.

039 "Can Education Save Europe From High Unemployment?" by Nicole Walter and Runli Xie, J une 2008.

042 "Gruppenvergleiche bei hypothetischen Konstrukten - Die Prüfung der Übereinstimmung von Messmodellen mit der Strukturgleichungsmethodik" by Dirk Temme and Lutz Hildebrandt, June 2008.

043 "Modeling Dependencies in Finance using Copulae" by Wolfgang Härdle, Ostap Okhrin and Yarema Okhrin, June 2008.

044 "Numerics of Implied Binomial Trees" by Wolfgang Härdle and Alena Mysickova, J une 2008.

045 "Measuring and Modeling Risk Using High-Frequency Data" by Wolfgang Härdle, Nikolaus Hautsch and Uta Pigorsch, June 2008.

046 "Links between sustainability-related innovation and sustainability management" by Marcus Wagner, June 2008.

\section{SFB 649, Spandauer Straße 1, D-10178 Berlin http:/ / sfb649.wiwi.hu-berlin.de}

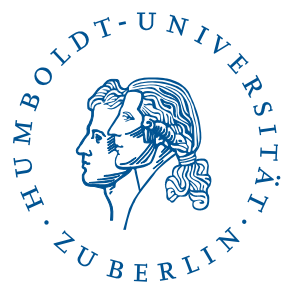


047 "Modelling High-Frequency Volatility and Liquidity Using Multiplicative Error Models" by Nikolaus Hautsch and Vahidin Jeleskovic, July 2008.

048 "Macro Wine in Financial Skins: The Oil-FX Interdependence" by Enzo Weber, July 2008.

049 "Simultaneous Stochastic Volatility Transmission Across American Equity Markets" by Enzo Weber, July 2008.

SFB 649, Spandauer Straße 1, D-10178 Berlin http:/ / sfb649.wiwi.hu-berlin.de

This research was supported by the Deutsche Forschungsgemeinschaft through the SFB 649 "Economic Risk".

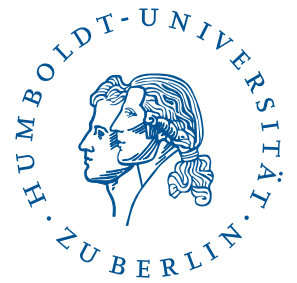

